\title{
The Effect of Interference of Mobile ADHOC Networks on WIMAX
}

\author{
Sajjan Virak \\ Research Scholar (ECE) \\ SBSSTC, Ferozepur
}

\author{
Amit Grover \\ Assistant Professor (ECE) \\ SBSSTC, Ferozepur
}

\begin{abstract}
In this paper the effect of interference of MANET on WIMAX is analyzed. To analyze the performance the MANET nodes are moved using different mobility patterns (Random walk and Random way point). The effect is also analyzed by varying number of cells and number of users. The performance has been analyzed in terms of throughput, traffic sent (voice) and traffic sent (video). The results show that the performance of WIMAX decreases as MANET nodes come into existence in the network but traffic sent (voice) and traffic sent (video) increases.
\end{abstract}

\section{Keywords}

WIMAX, MANET, OPNET.

\section{INTRODUCTION}

WiMAX is Wireless Interoperability for Microwave Access, it is the modern area used for research in Wireless Communication which is in view of the IEEE 802.16-2004 and IEEE 802.16e-2005 benchmarks and was outlined with much impact from Wi-Fi $[11,12]$. IEEE 802.16 backings two sorts of transmission duplexing: Time Division Duplexing (TDD) and Frequency Division Duplexing (FDD) and bolster both full and half duplex stations [10, 13]. WiMAX [7, 8]used orthogonal frequency division multiplexing (OFDM) which is a suitable modulation/access system for non-line-of-sight (LOS) conditions with high information rate $[1,2,9]$.MANET is a decentralized, self-organizing network which have a smart antennas for each node i.e. act as a transmitting and receiving data, which gives point to point communicationfrom a appropriate route in the presence of any one routing protocol like AODV, GRP(Gathering based routing protocol), DSR (Dynamic Source Routing), OLSR (Optimized Link State Routing) etc . At present time the MANET become one of the most important wireless communication mechanisms among all other.

\section{WIMAX STANDARDS}

WiMAX used the IEEE 802.16 standards. IEEE 802.16 provides one point to many points using 10 to $66 \mathrm{GHz}$ frequency range for Line of Sight [3].In 802.16astandard the ability to show one point to many points in the frequency range from 2 to $11 \mathrm{GHz}$. 802.16cstandard use frequency range 10 to $66 \mathrm{GHz} .802 .16$ dstandard backings obligatory and discretionary components alongside TDD and FDD technologies. It's using information rate is 40 to $70 \mathrm{Mbps}$. 802.16 ewas an adjustment of $802.16 \mathrm{~d}$ standard which is more fast $[4,5,6]$.

\section{WIMAX MODULE}

WiMAX uses five types of module for making a communication in between transmitter and receiver $[8,9,10$, 14]:
3.1 Base Station: Base station is the hub that constantly joins wireless endorser gadgets to administrator systems.

3.2 Subscriber Station: This is a stationary WiMAXproficient radio framework that communications with a base station.

3.3 Mobile Station: It is a subscriber station that is planned to be utilized while as a part of movement at up to vehicular paces.

3.4 Relay Station: These stations are subscriber station designed to forward movement to different relay station. Relay station is used to connect a building or portable.

3.5 Operator Network: The function is give radio access and IP network administrations to WiMAX subscribers.

\section{EXPERIMENTAL SETUP}

In this paper the effect of WIMAX and MANET network interference is analyzed by moving nodes of MANET at different mobility patterns (Random walk and Random way point) and WIMAX nodes are moving by using random waypoint only. This effect is further analyzed by increasing no. of cells and no. of nodes. Firstly 5 cells are used which have 5 nodes in each cell as shown in fig 1 then 6 cells are used as shown in fig 2 and 10 nodes are used in each cell and then no: of cells are increased to 7 cells as shown in fig 3 and having 15 nodes in each cell. In each scenario maximum retransmission is 4. In each scenario the no. of nodes of MANET remains the same which is 5. In each scenario the nodes have application of voice and video both. For video SVC code is used. These scenarios are repeated by using maximum retransmission 2 .

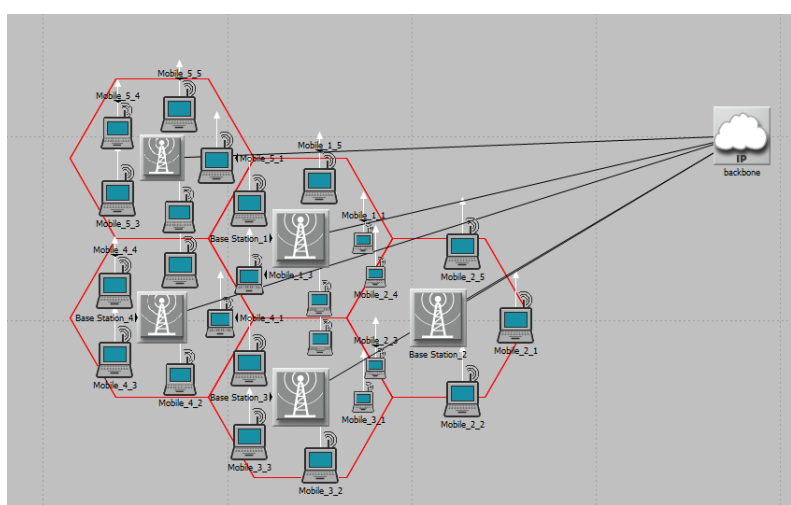

Fig 1: Cell 5 


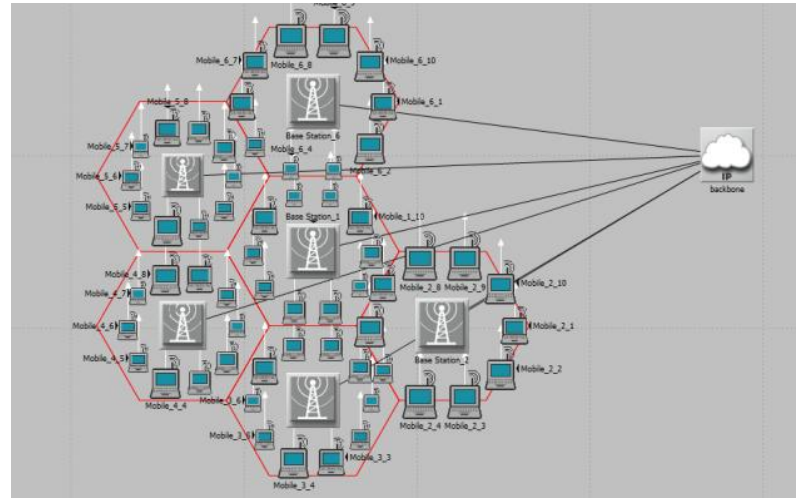

Fig 2: Cell 6

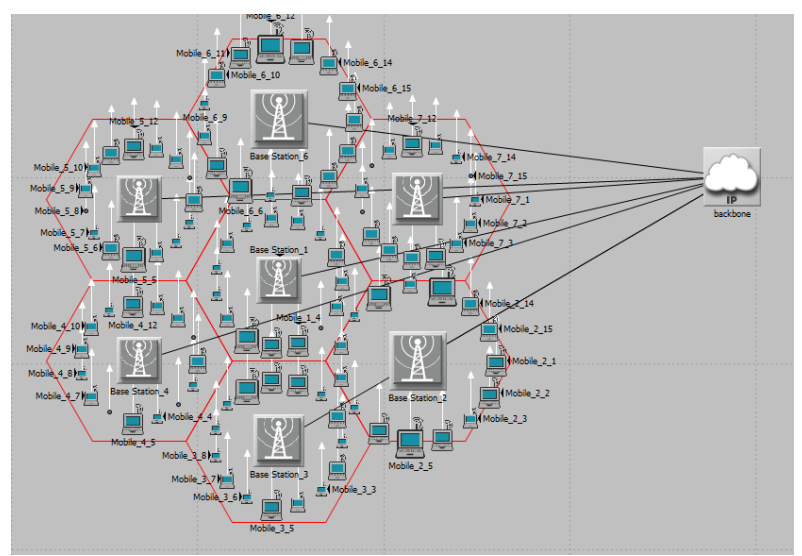

Fig 3: Cell 7

\section{RESULTS AND DISCUSSIONS}

In this research work the effect of MANET on WIMAX is analyzed in terms of throughput, traffic sent (video), traffic sent (voice).

\subsection{Throughput}

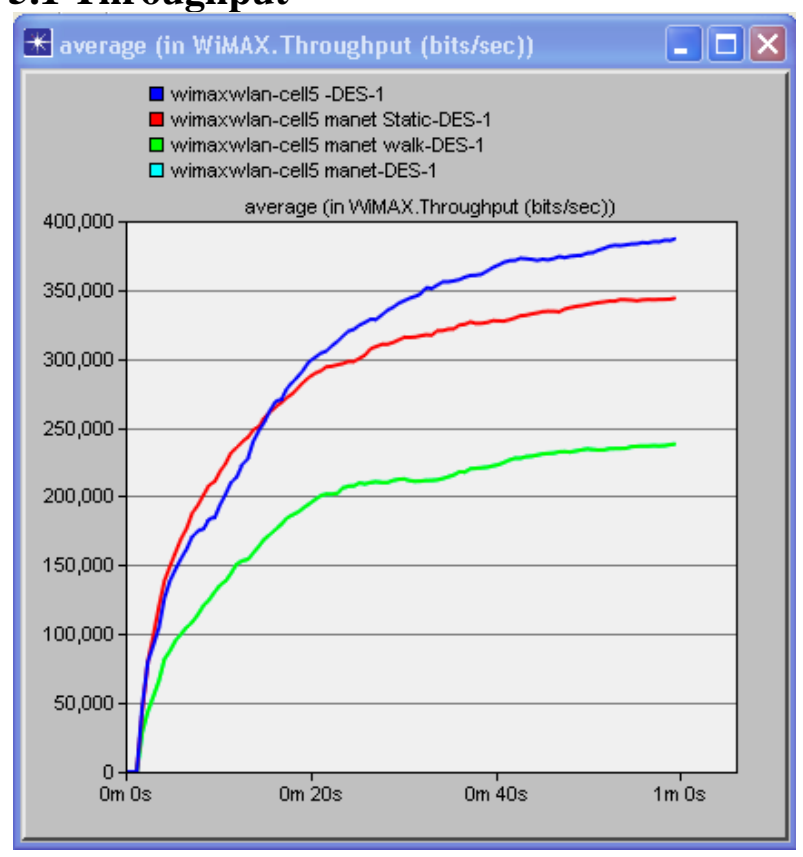

Fig 4: Throughput for cell 5

Fig4 shows the result of throughput for cell 5. Result shows that when there is no MANET node than throughput is high which is 400000 bits/sec and when MANET nodes come into existence then throughput decreases. Further if nodes move with static mobility pattern then result is high which is 350000 bits/sec. For random walk and Random Way point it is same which is $250000 \mathrm{bits} / \mathrm{sec}$.

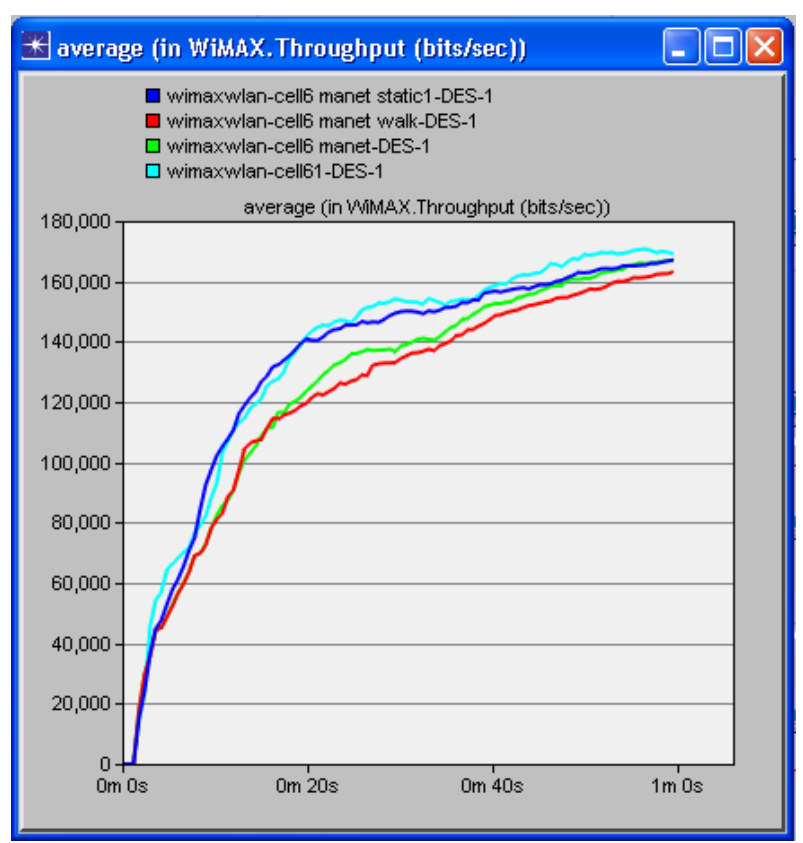

Fig 5: Throughput for cell 6

Fig5 shows the result of throughput for cell 6. Result shows that when there is no MANET node that throughput is high which is $170000 \mathrm{bits} / \mathrm{sec}$ and when MANET nodes come into existence then throughput decreases. Further if nodes move with static mobility pattern and Random Way point then result is same which is $167000 \mathrm{bits} / \mathrm{sec}$ and for random walk it is $163000 \mathrm{bits} / \mathrm{sec}$.

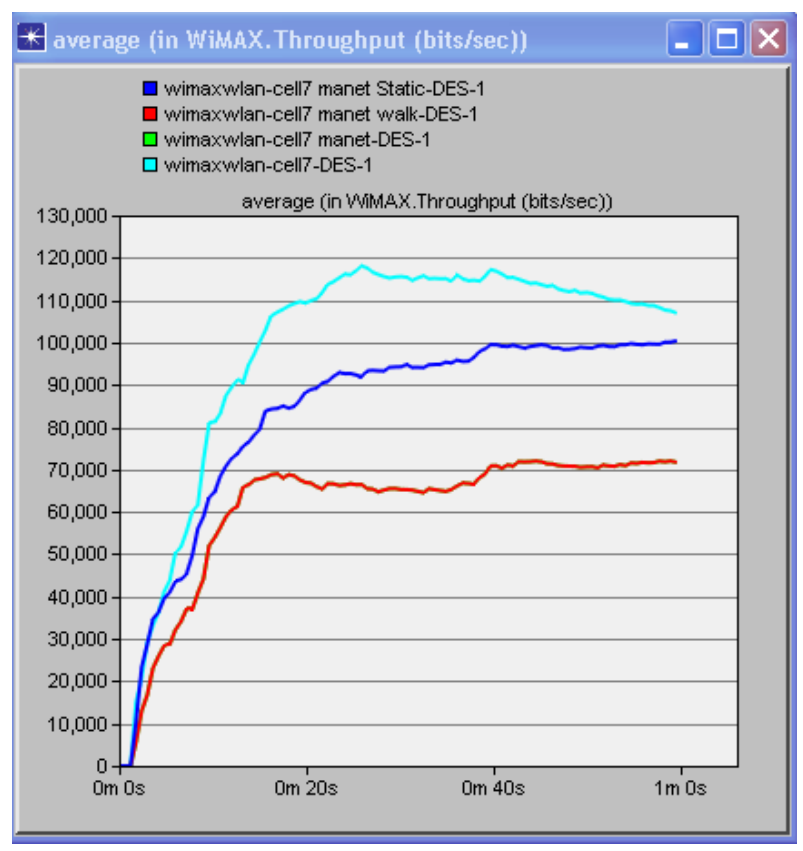

Fig 6: Throughput for cell 7

Fig 6 shows the result of throughput for cell 7. Result shows that when there is no MANET node that throughput is high which is $110000 \mathrm{bits} / \mathrm{sec}$ and when MANET nodes come into 
existence then throughput decreases. Further if nodes move with static mobility pattern then result is high which is 100000 bits/sec for random walk and Random Way point it same which is $70000 \mathrm{bits} / \mathrm{sec}$.

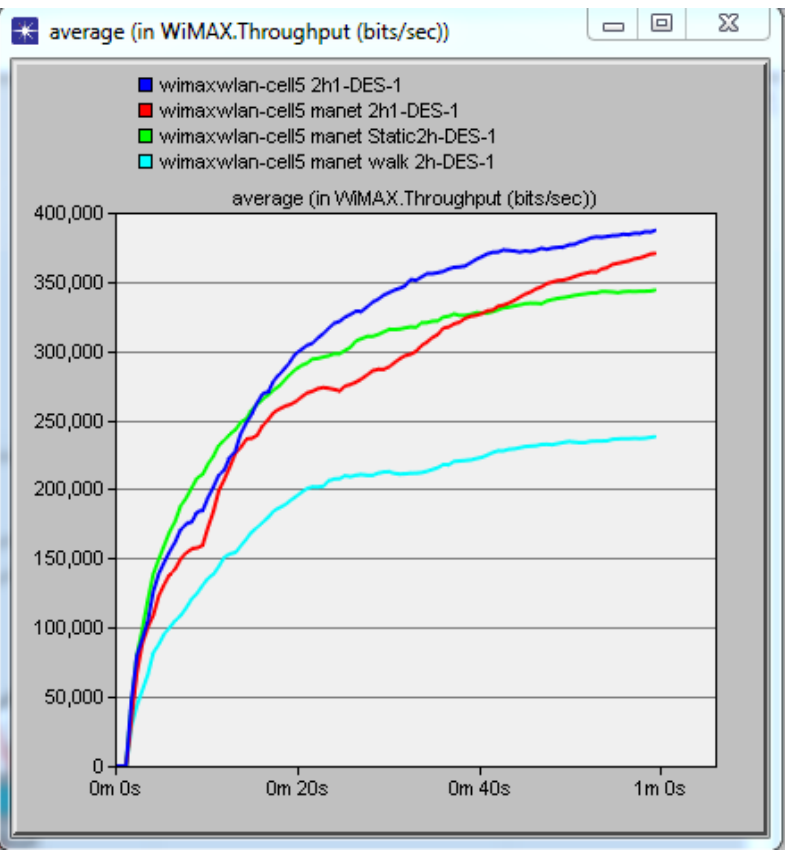

Fig 7: Throughput for cell 5 with maximum retransmission attempt 2

Fig7 shows the result of throughput for cell 5 with maximum retransmission attempt 2. Result shows that when there is no MANET node that throughput is high which $380000 \mathrm{bits} / \mathrm{sec}$ is and when MANET nodes come into existence then throughput decreases. Further if nodes move with static mobility pattern then result is 350000 bits/sec for random walk it is $360000 \mathrm{bits} / \mathrm{sec}$ and for Random Way point it is $240000 \mathrm{bits} / \mathrm{sec}$.

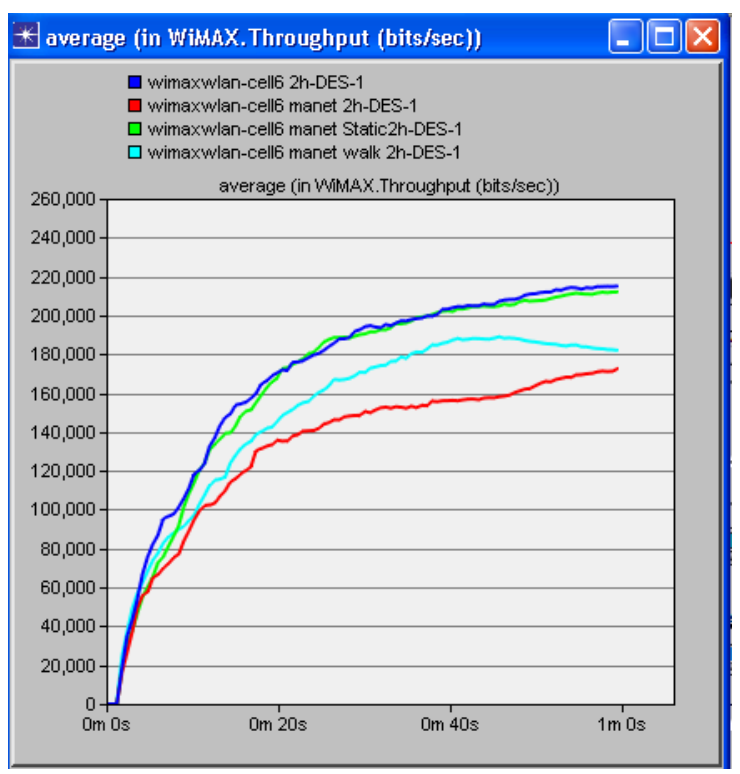

Fig 8: Throughput for cell 6 with maximum retransmission attempt2

Fig8 shows the result of throughput for cell 6 with maximum retransmission attempt 2 . Result shows that when there is no MANET node that throughput is high which is 210000bits/sec and when MANET nodes come into existence then through put decreases. Further if nodes move with static mobility pattern it is $210000 \mathrm{bits} / \mathrm{sec}$ and for Random Way point result is $170000 \mathrm{bits} / \mathrm{sec}$ and for random walk it is $180000 \mathrm{bits} / \mathrm{sec}$.

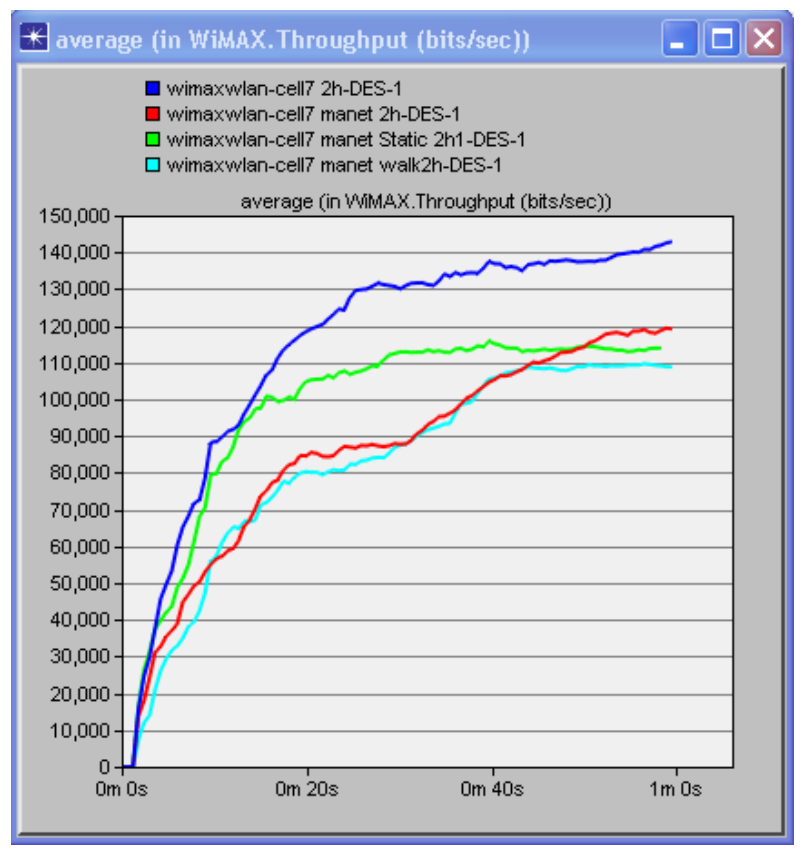

Fig 9: Throughput for cell 7 with maximum retransmission attempt 2

Fig 9 shows the result of throughput for cell 7 maximum retransmission attempt 2 . Result shows that when there is no MANET node that throughput is high which is 140000 bits/sec and when MANET nodes come into existence then throughput decreases. Further if nodes move with static mobility pattern and Random Way point result is high which is $120000 \mathrm{bits} / \mathrm{sec}$ and for random walk it is $110000 \mathrm{bits} / \mathrm{sec}$.

\subsection{Traffic sent for video}

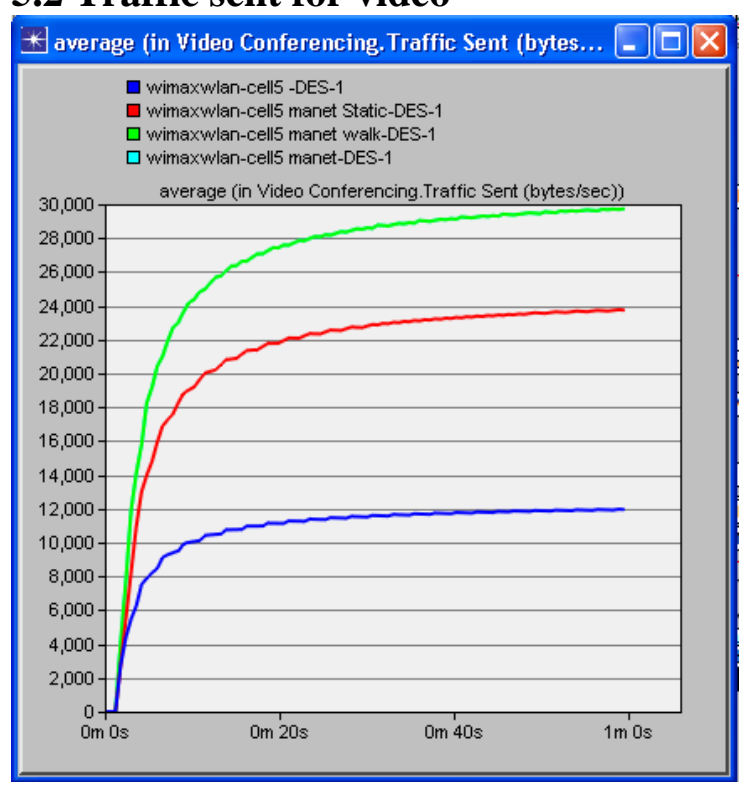

Fig 10: Traffic sent for video for cell 5

Fig10 shows the result of Traffic sent for video for cell 5 . Result shows that when there is no MANET node that Traffic sent is less which is $13000 \mathrm{bits} / \mathrm{sec}$ and when MANET nodes come into existence then Traffic sent increases because they 
also send video packets. Further if nodes move with static mobility pattern then result is $24000 \mathrm{bits} / \mathrm{sec}$ for random walk and Random Way point it is same which is $30000 \mathrm{bits} / \mathrm{sec}$.

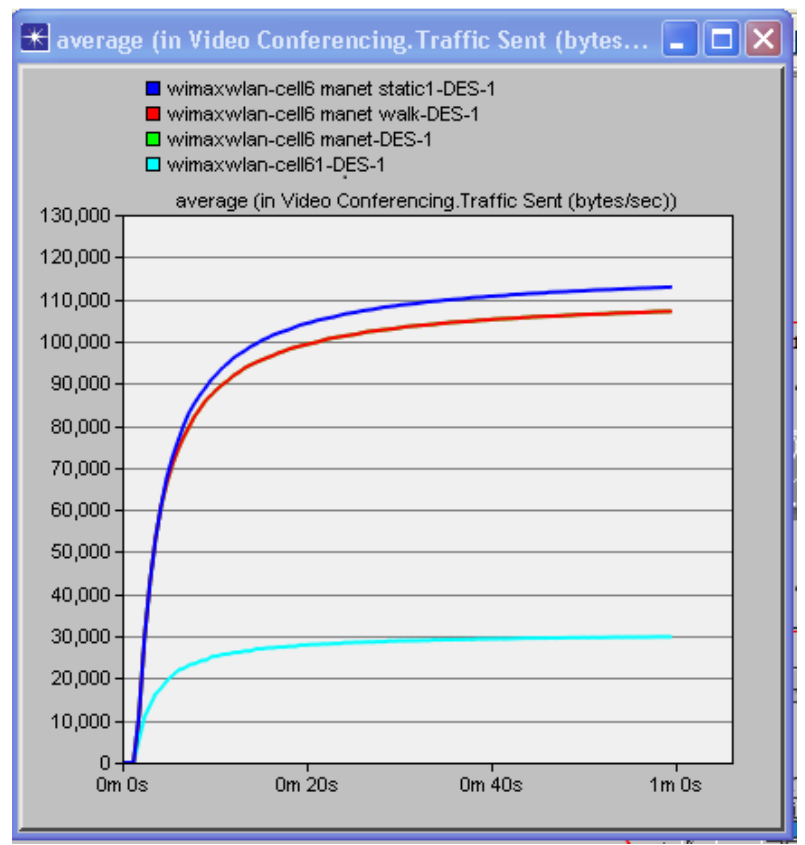

Fig 11: Traffic sent for video for cell 6

Fig 11 shows the result of Traffic sent for video for cell 6 . Result shows that when there is no MANET node that Traffic sent is less which is $30000 \mathrm{bits} / \mathrm{sec}$ and when MANET nodes come into existence then Traffic sent increases because they also send video packets. Further if nodes move with static mobility pattern then result is $110200 \mathrm{bits} / \mathrm{sec}$ for random walk and Random Way point it is same which is 100700 bits/sec.

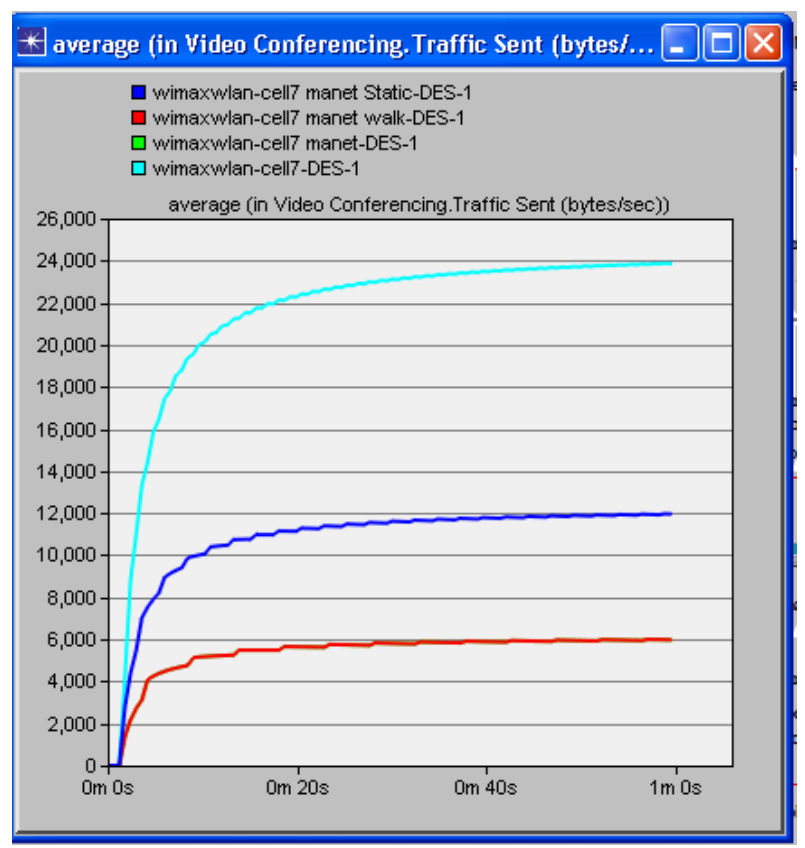

Fig 12: Traffic sent for video for cell 7

Fig12 shows the result of Traffic sent for video for cell 7 . Result shows that when there is no MANET node that Traffic sent is less which is $24000 \mathrm{bits} / \mathrm{sec}$ and when MANET nodes come into existence than Traffic sent increases because they also send video packets. Further if nodes move with static mobility pattern than result is $13000 \mathrm{bits} / \mathrm{sec}$ for random walk and Random Way point it is same which is $7000 \mathrm{bits} / \mathrm{sec}$.

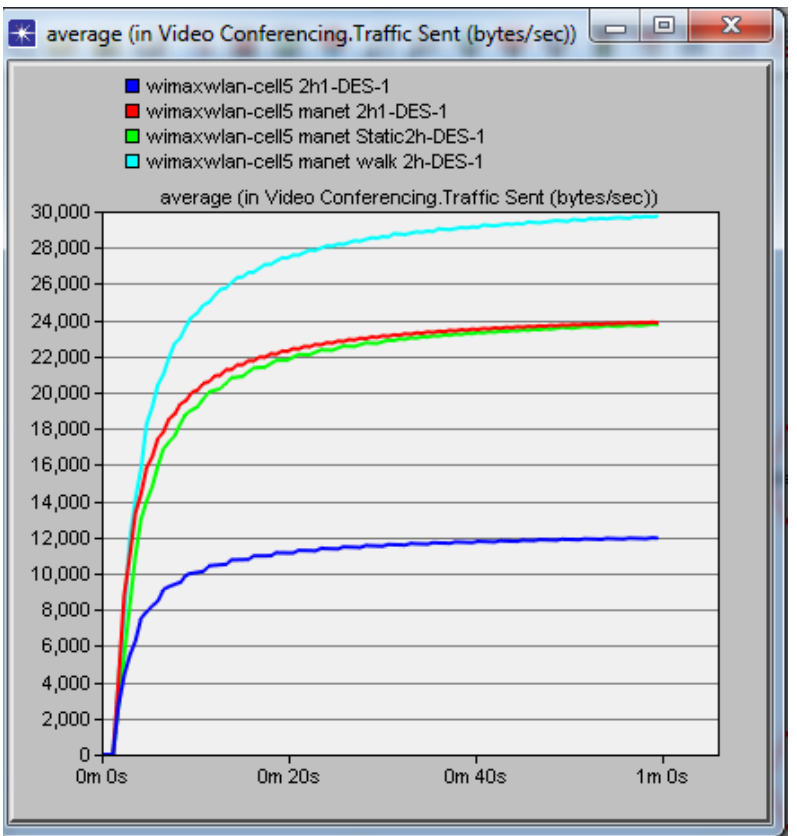

Fig 13: Traffic sent for video for cell 5 for maximum retransmission attempt 2

Fig 13 shows the result of Traffic sent for video for cell 5 for maximum retransmission attempt 2 . Result shows that when there is no MANET node that Traffic sent is less which is $30000 \mathrm{bits} / \mathrm{sec}$ and when MANET nodes come into existence then Traffic sent increases because they also send video packets. Further if nodes move with static mobility pattern and Random Way point it is same which is $24000 \mathrm{bits} / \mathrm{sec}$ for random walk it is $30000 \mathrm{bits} / \mathrm{sec}$.

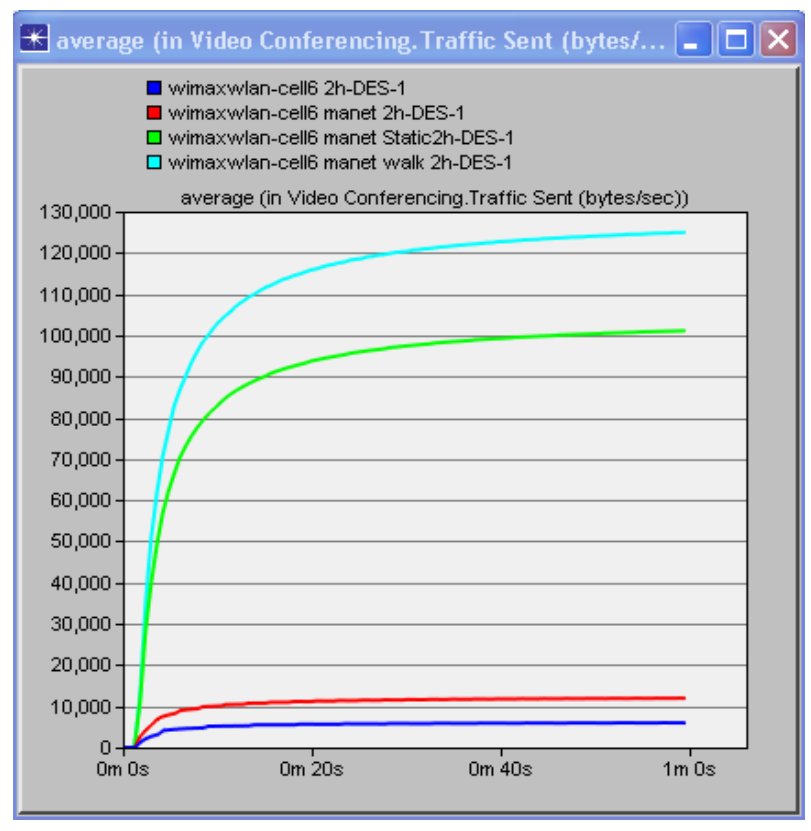

Fig 14: Traffic sent for video for cell 6 for maximum retransmission attempt 2

Fig14 shows the result of Traffic sent for video for cell 6 for maximum retransmission attempt 2. Result shows that when there is no MANET node that Traffic sent is less which is 
$5000 \mathrm{bits} / \mathrm{sec}$ and when MANET nodes come into existence than Traffic sent increases because they also send video packets. Further if nodes move with static mobility pattern then result is $100000 \mathrm{bits} / \mathrm{sec}$ and for random walk it is 121000 bits/sec and for Random Way point it is 11000 bits/sec.

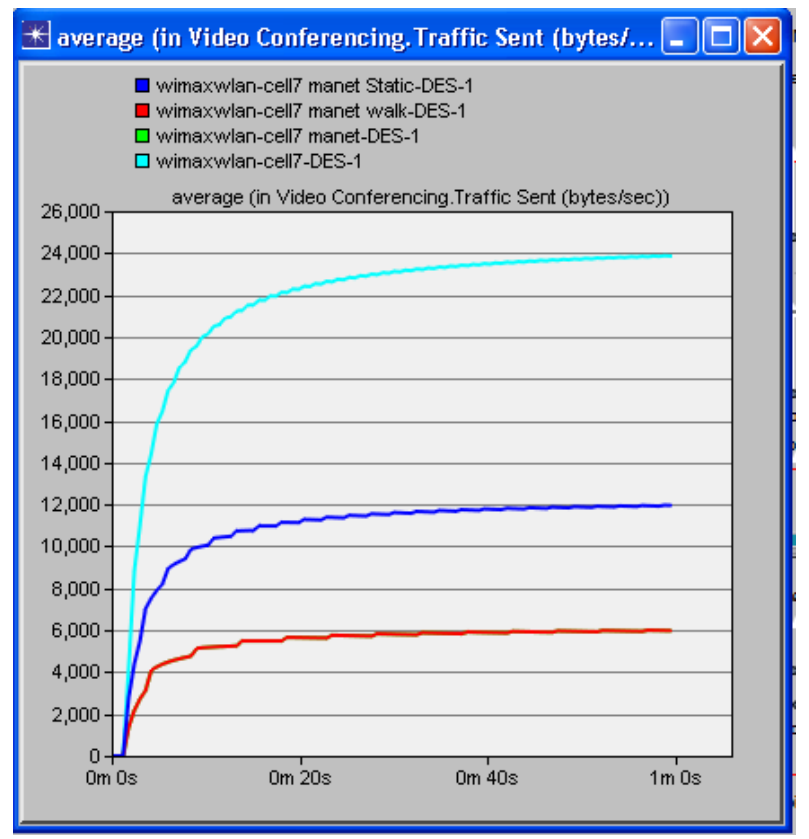

Fig 15: Traffic sent for video for cell 7 for maximum retransmission attempt 2

Fig 15 shows the result of Traffic sent for video for cell 7 maximum retransmission attempts 2 . Result shows that when there is no MANET node that Traffic sent is $12000 \mathrm{bits} / \mathrm{sec}$ and when MANET nodes come into existence then Traffic sent increases because they also send video packets. Further if nodes move with static mobility pattern and random walk and Random Way point it is same which is $6000 \mathrm{bits} / \mathrm{sec}$

\subsection{Traffic sent for voice}

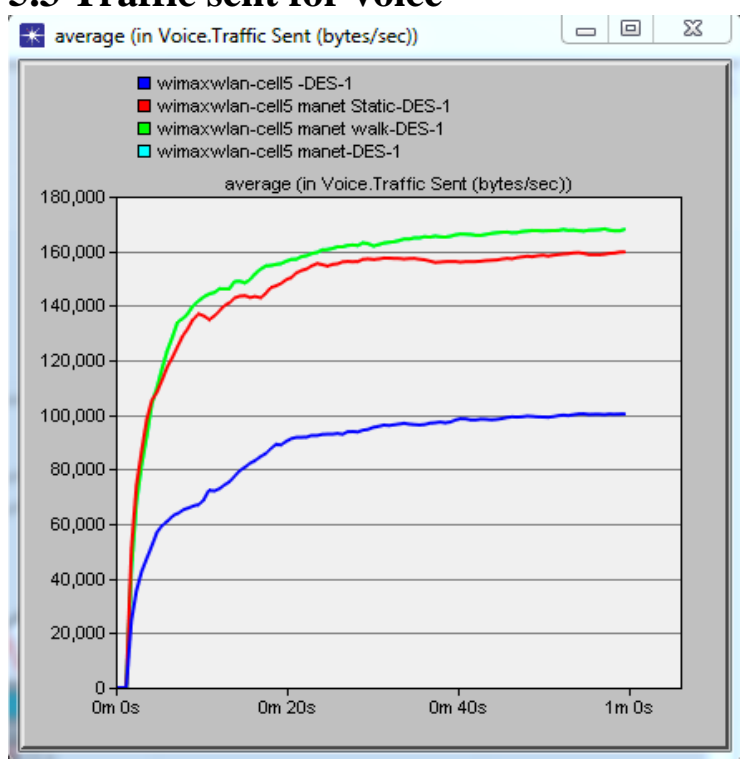

Fig 16: Traffic sent for video for cell 5

Fig 16 shows the result of Traffic sent for voice for cell 5 . Result shows that when there is no MANET node that Traffic sent is less which is $100000 \mathrm{bits} / \mathrm{sec}$ and when MANET nodes come into existence than Traffic sent increases because they also send voice packets. Further if nodes move with static mobility pattern than result is $160000 \mathrm{bits} / \mathrm{sec}$ for random walk and for Random Way point it is same which is 170000 bits/sec.

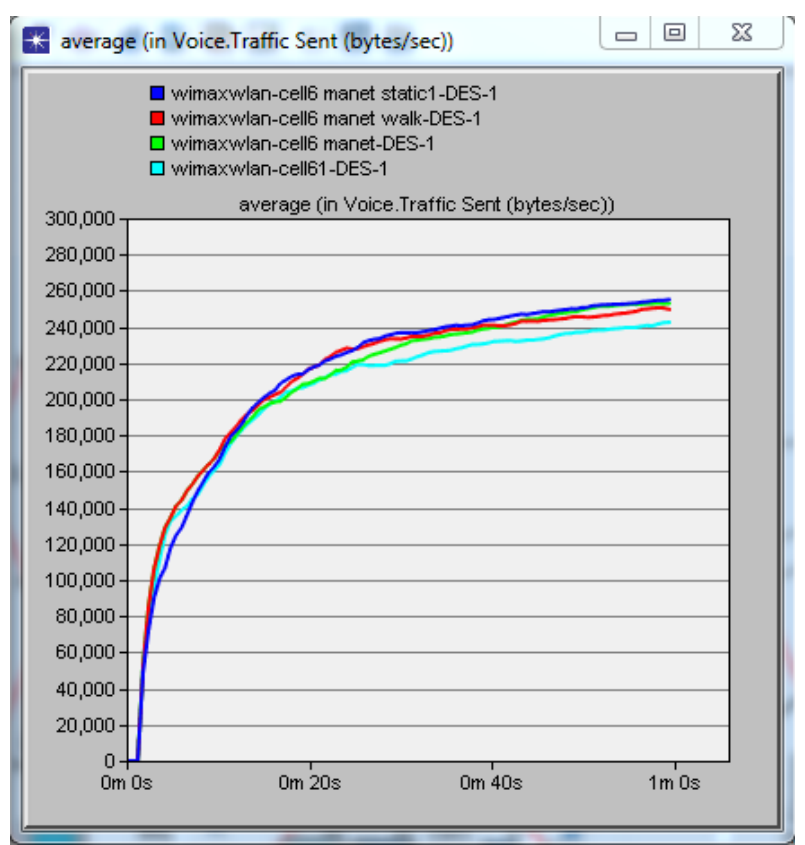

Fig 17: Traffic sent for video for cell 6

Fig 17 shows the result of Traffic sent for voice for cell 6 . Result shows that when there is no MANET node that Traffic sent is less which is 242000bits/sec and when MANET nodes come into existence then Traffic sent increases because they also send voice packets. Further if nodes move with static mobility pattern then result is $255000 \mathrm{bits} / \mathrm{sec}$ for random walk it is $249000 \mathrm{bits} / \mathrm{sec}$ and for Random Way point it is $252000 \mathrm{bits} / \mathrm{sec}$.

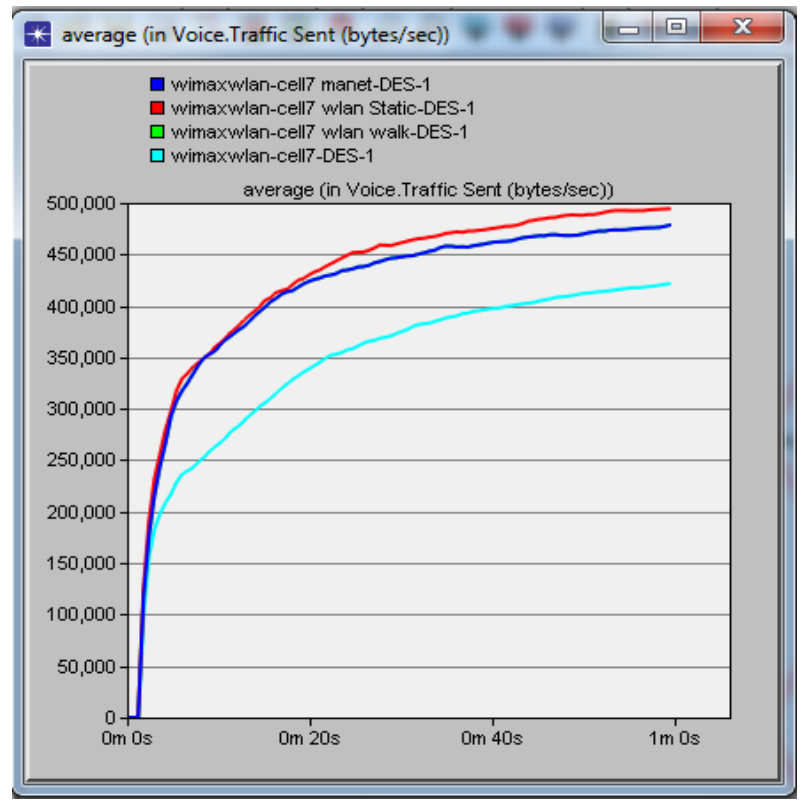

Fig 18: Traffic sent for video for cell 7

Fig 18 shows the result of Traffic sent for voice for cell 7 . Result shows that when there is no MANET node that Traffic sent is small which is $420000 \mathrm{bits} / \mathrm{sec}$ and when MANET 
nodes come into existence than Traffic sent increases because they also send video packets. Further if nodes move with static mobility pattern then result is $500000 \mathrm{bits} / \mathrm{sec}$ for random walk and Random Way point it is same which is $455000 \mathrm{bits} / \mathrm{sec}$.

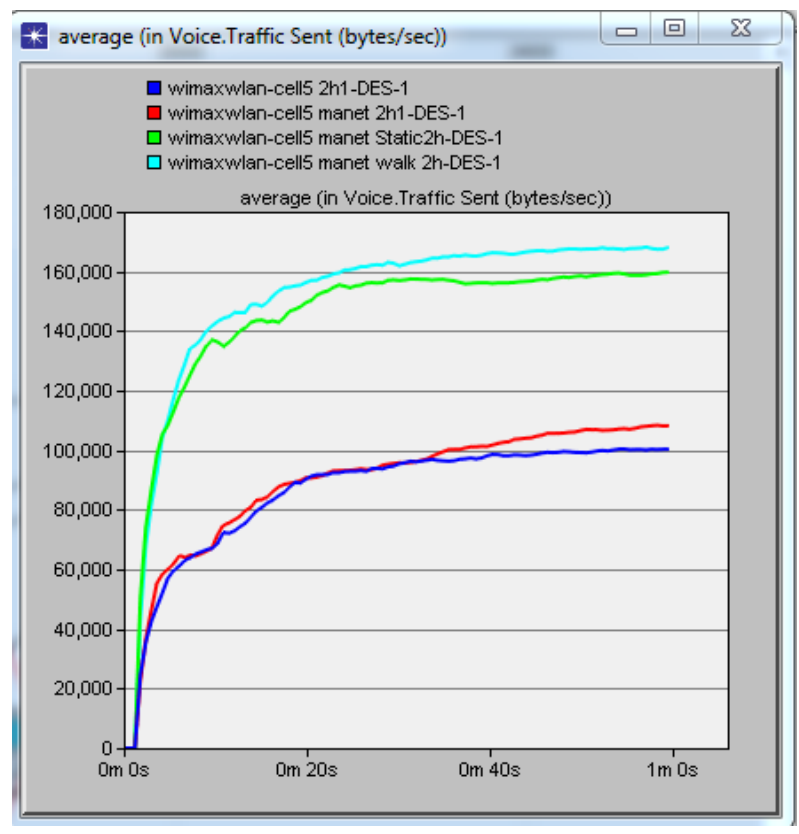

Fig 19: Traffic sent for video for cell 5 for maximum retransmission attempt 2

Fig 19 shows the result of Traffic sent for voice for cell 5 for maximum retransmission attempt 2 . Result shows that when there is no MANET node that Traffic sent is less which is $100000 \mathrm{bits} / \mathrm{sec}$ and when MANET nodes come into existence than Traffic sent increases because they also send voice packets. Further if nodes move with static mobility pattern it is 160000bits/sec and Random Way point is 108000 bits/sec and for random walk it is $170000 \mathrm{bits} / \mathrm{sec}$.

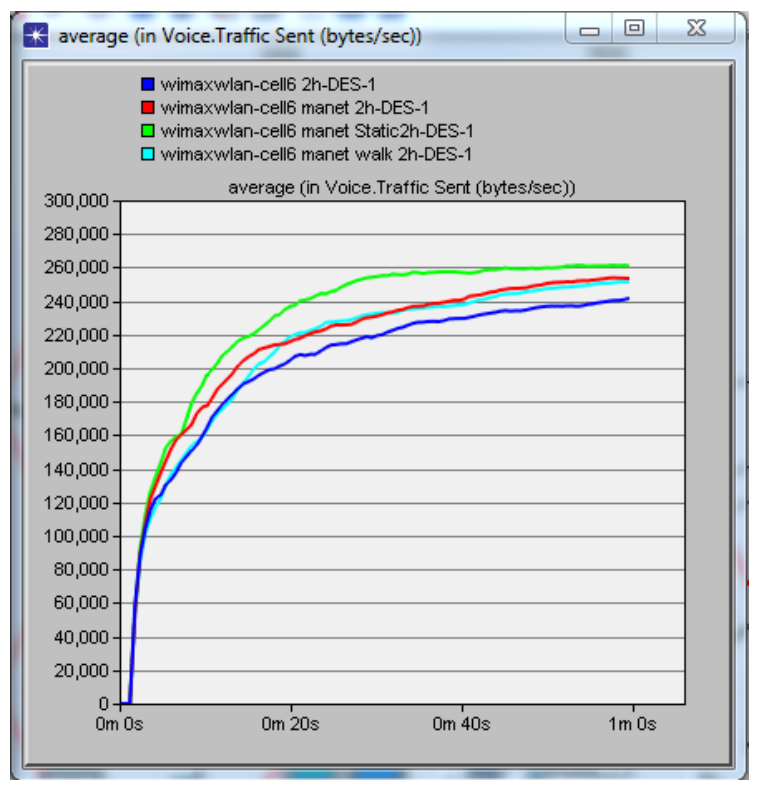

Fig 20: Traffic sent for video for cell 6 for maximum retransmission attempt 2

Fig 20 shows the result of Traffic sent for voice for cell 6 for maximum retransmission attempt 2 . Result shows that when there is no MANET node that Traffic sent is 240000bits/sec. Further if nodes move with static mobility pattern then result is 240000 bits/sec and for random walk and Random Way point it is $260000 \mathrm{bits} / \mathrm{sec}$.

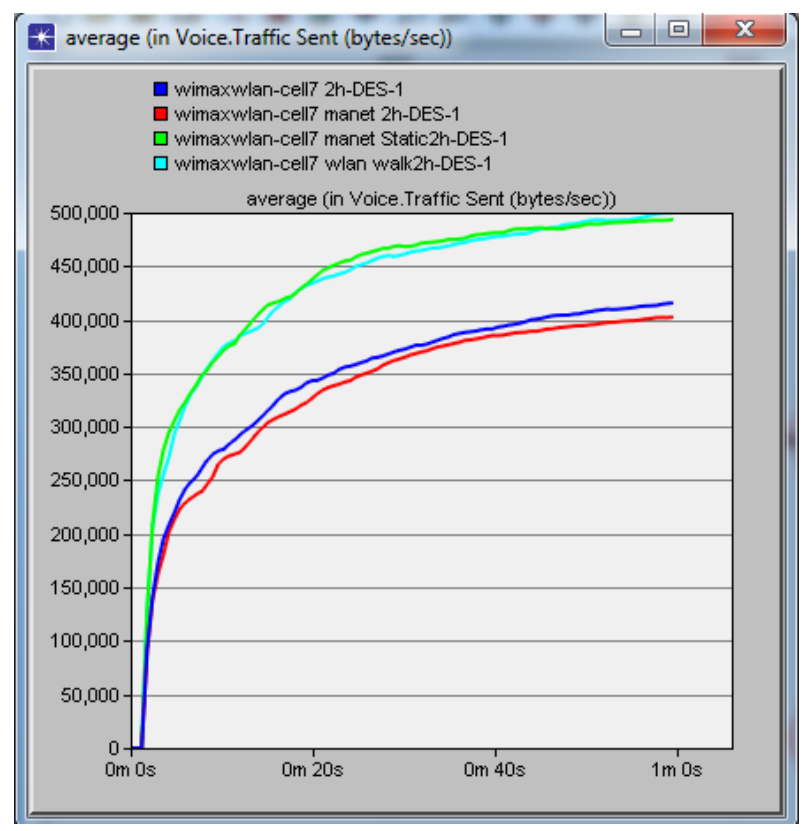

Fig 21: Traffic sent for video for cell 7 for maximum retransmission attempt 2

Fig 21shows the result of Traffic sent for voice for cell 7 for maximum retransmission attempt 2. Result shows that when there is no MANET node that Traffic sent is $410000 \mathrm{bits} / \mathrm{sec}$ and when MANET nodes come into existence then Traffic sent increases because they also send video packets. Further if nodes move with static mobility pattern then result is 500000 bits/sec for random walk it is $400000 \mathrm{bits} / \mathrm{sec}$ and Random Way point it is $400000 \mathrm{bits} / \mathrm{sec}$.

\section{CONCLUSIONS}

In this paper the QOS of WIMAX is analyzed in presence of MANET. To analyze QOS, MANET nodes are moved using different mobility patterns. The performance of WIMAX is further analyzed by increasing no. of cells and no. of nodes. This performance is analyzed in terms of throughput, traffic sent(voice) and traffic sent (video). The results show that the performance of WIMAX decreases as MANET nodes come into existence in the network but traffic sent(voice) and traffic sent (video) increases. Further if maximum retransmission attempt decreases then throughput increases but sent (voice) and traffic sent (video) decreases.

\section{REFERENCES}

[1] Ghosh A. Wolter, D.R., "Broadband wireless access with WiMax/802.16: current performance benchmarks and future potential", Communications Magazine, IEEE (Volume:43, Issue: 2 ),2005.

[2] Hung-Yu Wei, Ganguly S., "Interference-aware IEEE 802.16 WiMax mesh networks" Vehicular Technology Conference. VTC-Spring. IEEE 61st (Volume:5),2005.

[3] Chakchai So-In, Jain, R., "Scheduling in IEEE 802.16e mobile WiMAX networks: key issues and a survey," IEEE Journal on (Volume:27, Issue: 2 ),2009. 
[4] Deb, S. Bell Labs, "Real-Time Video Multicast in WiMAX Networks", INFOCOM The 27th Conference on Computer Communications. IEEE,2008.

[5] Schwarz, H.,Heinrich Hertz, "Overview of the Scalable Video Coding Extension of the H.264/AVC Standard" ,Circuits and Systems for Video Technology, IEEE Transactions on (Volume:17, Issue: 9, 2007.

[6] Pentikousis, K. Pinola, J., "An experimental investigation of VoIP and video streaming over fixed WiMAX" , Modeling and Optimization in Mobile, Ad Hoc, and Wireless Networks and Workshops, 2008.

[7] Will Hrudey, "Streaming Video Content Over IEEE 802.16 / WiMAX Broadband Access”, Spring 2008.

[8] Sharangi, S. Krishnamurti, R., "Energy-Efficient Multicasting of Scalable Video Streams Over WiMAX Networks" Multimedia, IEEE Transactions on (Volume:13, Issue: 1 )2010.

[9] Yong Liu, Yang Guo, Chao Liang, "A survey on peerto-peer video streaming systems" peer-to-Peer Networking and Applications, Volume 1, Issue 1, pp 1828, 2008.
[10] Y. Wang, “ Survey of Objective Video Quality Measurements, Tech report," Worcester Polytechnic Institute, June 2006.

[11] C. Cicconetti, C. Eklund, L. Lenzini, E. Mingozzi, “ Quality of service support in IEEE 802.16 Networks", IEEE Network 20 (2006).

[12] J. Casasempere, P. Sanchez, "Performance evaluation of H.264/MPEG-4 Scalable Video Coding over IEEE 802.16e networks"IEEE International Symposium on, 13-15 May 2009.

[13] Mengke Hu, Hongguang Zhang, “Performance evaluation of video streaming over mobile WiMAX networks", GLOBECOM Workshops (GC Wkshps), 2010 IEEE, vol., no., pp.898-902, 6-10 Dec. 2010.

[14] S. Winkler, P. Mohandas, "The evolution of video quality measurement: from PSNR to hybrid metrics", IEEE Transactions on Broadcasting 54 (2008).

[15] T. Wiegand, G.J. Sullivan, G. Bjontegaard, "Overview of the h.264/ave video coding standard", IEEE Transactions on Circuits and Systems for Video Technology (2003). 